\title{
Allelic heterogeneity of alkaptonuria in Central Europe
}

\author{
CR Müller ${ }^{1}$, A Fregin ${ }^{1}$, S Srsen ${ }^{2}$, K Srsnova ${ }^{2}$, B Halliger-Keller ${ }^{1}$, U Felbor ${ }^{1}$, \\ E Seemanova $^{3}$ and W Kress ${ }^{1}$ \\ ${ }^{1}$ Department of Human Genetics, University of Würzburg, Biozentrum, Würzburg, Germany \\ ${ }^{2}$ Jessenius Faculty of Medicine, Komensky University of Martin, Slovak Republic \\ ${ }^{3}$ Department of Medical Genetics, 2nd Medical Faculty, Charles University Prague, Czech Republic
}

\begin{abstract}
Defects of the homogentisate 1,2 dioxygenase (HGO; E.C. No. 1.13.11.5) have been identified as the molecular cause of alkaptonuria in humans (AKU) and the aku mouse. Here, we report on the genetic basis of $30 \mathrm{AKU}$ patients from Central Europe. In addition to five mutations described previously, we have detected five novel HGO mutations. Recombinant expression of mutated HGO enzymes in $E$. coli demonstrates the inactivating effect of three of these mutations. A genetic epidemiologic study in Slovakia, the country with the highest incidence of alkaptonuria, demonstrates that two recurrent mutations (c.183-1G $>A$ and Gly161Arg) are found on more than $50 \%$ of $\mathrm{AKU}$ chromosomes. An analysis of the allelic association with intragenic DNA markers and of the geographic origins of the AKU chromosomes suggests that several independent founders have contributed to the gene pool, and that subsequent genetic isolation is likely to be responsible for the high prevalence of alkaptonuria in Slovakia.
\end{abstract}

Keywords: alkaptonuria; homogentisate 1,2 dioxygenase; mutation detection; recombinant expression; genetic epidemiology; founder effect

\section{Introduction}

Alkaptonuria (AKU, OMIM No. 203500) is the classic example of a metabolic disorder in humans. The excretion of large amounts of 2,5 dihydroxyphenylacetic acid (homogentisic acid, HGA) with the pathognomonic urina nigra of alkaptonuric patients led AE Garrod to hypothesise on a specific metabolic block in the degradation of phenylalanine and tyrosine. In 1908, Garrod extended this notion into his general concept of 'inborn errors of metabolism' (for review see

Correspondence: Prof. CR Müller, PhD, Department of Human Genetics, University of Würzburg, Biozentrum, Am Hubland, D-97074 Würzburg, Germany. Tel: + 49931888 4063; Fax: + 49931888 4069; E-mail: crm@biozentrum.uniwuerzburg.de

Received 15 December 1998; revised 5 March 1999; accepted 9 March 1999
$\mathrm{La} \mathrm{Du}^{1}$ and O'Brien et $a l^{2}$ ). The high numbers of consanguineous parents of affected children further suggested alkaptonuria to him as one of the first examples of a recessive genetic disease in man which conforms to the first Mendelian law.

Experimental proof of Garrod's postulate came 50 years later. The complete deficiency of homogentisic acid 1,2 dioxygenase activity (HGO; E.C. No. 1.13.11.5) in the liver of an AKU patient was identified as the missing step in the catabolism of tyrosine. ${ }^{3}$ This metabolic block explains the accumulation of the intermediary product homogentisate which gives rise to the main clinical symptoms, dark urine and ochronosis. Over the years, polymers of benzoquinone acetic acid are formed from the excess homogentisate and are deposited in cartilage and collagenous tissue as the ochronotic pigment. This can lead to painful and disabling arthropathy of the large joints. ${ }^{2}$ However, in 
contrast to other metabolic disorders, intellectual capacity and life expectancy are not compromised in alkaptonuria.

The molecular basis of AKU has only recently been elucidated. As the first gene from any species the $h g m A$ gene of Aspergillus was cloned. ${ }^{4}$ The human cDNA was identified by sequence similarity in the EST database. ${ }^{5}$ Inactivating missense and frame-shift mutations established HGO defects as the molecular cause of alkaptonuria in man. ${ }^{5-9}$ Independently, the murine $\mathrm{HGO}$ cDNA was cloned using amino acid sequence information of the purified enzyme. ${ }^{10,11}$ The mutation of the $a k u$ mouse, induced by chemical mutagenesis, inactivates a splice donor site. ${ }^{12}$

The disease has been found at low prevalence (about 1 in 250000) in all ethnic groups studied. Notable exceptions are the Dominican Republic and Slovakia where much higher incidence has been reported. ${ }^{13,14}$ Founder effects as the consequence of migration and genetic isolation have been postulated to explain this observation. Here, we report on HGO mutations in 30 patients from 19 families in Central Europe and on allelic association studies of alkaptonuria patients from the Slovak Republic.

\section{Patients, Materials and Methods}

In the Slovak Republic, 21 patients from 12 families have been ascertained by SS and KS. The clinical diagnosis of alkaptonuria and the chromatographic determination of HGA were performed as described elsewhere. ${ }^{14,15}$ In the Czech Republic five patients from four families were referred by ES, and four German patients from three families were referred by clinicians. In one pedigree there were four patients; another pedigree had three affected members; six families had two affected relatives; the remaining 11 families had uniplex cases.

DNA was extracted from lymphocytes by standard procedures. Mutation screening in the $H G O$ gene was done by amplification of all exons from genomic DNA, followed by SSCP and direct sequencing as reported earlier ${ }^{6}$ or by restriction enzyme digests as listed in Table 1. Intragenic DNA markers D3S4556 and D3S4497 were typed according to existing procedures. ${ }^{7,16}$

Murine $\mathrm{HGO} \mathrm{cDNA}^{13}$ was cloned into the expression vector pQE-30 ${ }^{\mathrm{TM}}$ (Quiagen, Hilden, Germany) and transfected into the E. coli strain M15. Site-directed mutagenesis with the QuickChange ${ }^{\mathrm{TM}}$ kit (Stratagene, Heidelberg, Germany) was used to introduce human AKU mutations. Mutant clones were verified by sequencing. Western blots of $E$. coli extracts with $\mathrm{HGO}$ antibodies confirmed that all recombinant proteins were produced in equivalent amounts (data not shown). Recombinant HGO activity was measured by spectrophotometry. ${ }^{12}$

Table 1 Mutations of the $H G O$ gene in 30 alkaptonuria patients

\begin{tabular}{|c|c|c|c|c|c|c|c|c|}
\hline $\begin{array}{l}\text { Nucleotide } \\
\text { position }^{\mathrm{a}}\end{array}$ & $\begin{array}{l}\text { Amino acid } \\
\text { exchange }\end{array}$ & Exon/intron & $\begin{array}{l}\text { Predicted } \\
\text { effect }\end{array}$ & $\begin{array}{c}\text { Mutation } \\
\text { detection by }\end{array}$ & $\begin{array}{l}\text { No. of } A K U \\
\text { chromosomes }\end{array}$ & $\begin{array}{c}\text { No. of } \\
\text { families }\end{array}$ & $\begin{array}{c}\text { Geographic } \\
\text { origin }\end{array}$ & Reference \\
\hline c. $183-1 \mathrm{G}>\mathrm{A}$ & & $\begin{array}{l}\text { splice acceptor } \\
\text { site intron } 1\end{array}$ & $\begin{array}{c}\text { exon } \\
\text { skipping }\end{array}$ & $R s a$ I loss & 9 & 5 & $\begin{array}{l}3 \text { Slovak } \\
2 \text { Czech }\end{array}$ & this study \\
\hline c. $241 \mathrm{~T}>\mathrm{C}$ & Leu25Pro & exon 2 & missense & Aci I gain & 2 & 1 & German & this study \\
\hline c. $.509+1 \mathrm{G}>\mathrm{A}$ & & $\begin{array}{l}\text { splice donor site } \\
\text { intron } 5\end{array}$ & $\begin{array}{l}\text { exon } \\
\text { skipping }\end{array}$ & SSCP & 1 & 1 & Czech & this study \\
\hline c.642insG & Gly152fs & exon 7 & $\begin{array}{l}\text { truncated } \\
\text { protein }\end{array}$ & SSCP & 6 & 2 & Slovak & Ref. 6 \\
\hline c. $648 \mathrm{G}>\mathrm{A}$ & Gly161Arg & exon 8 & missense & Bsl I loss & 22 & 11 & $\begin{array}{c}7 \text { Slovak } \\
3 \text { Czech } \\
1 \text { German }\end{array}$ & Ref. 6 \\
\hline c. $855 \mathrm{C}>\mathrm{T}$ & Pro230Ser & exon 10 & missense & Eco RV gain & 2 & 1 & Slovak & Refs. 5,8 \\
\hline c. $975 \mathrm{G}>\mathrm{A}$ & Gly270Arg & exon 11 & missense & Eco NI gain & 1 & 1 & Slovak & this study \\
\hline c. $1066 \mathrm{~T}>\mathrm{G}$ & Val300Gly & exon 12 & missense & SSCP & 4 & 2 & Slovak & Ref. 5 \\
\hline c. $1269 A>G$ & Met368Val & exon 13 & missense & Mae III gain & 5 & 2 & German & Ref. 7 \\
\hline c.1278insC & Pro370fs & exon 13 & $\begin{array}{l}\text { truncated } \\
\text { protein }\end{array}$ & SSCP & 6 & 3 & Slovak & this study \\
\hline
\end{tabular}

${ }^{a}$ Numbering of nucleotides starts at the transcription initiation site. ${ }^{16}$ The ATG start codon is at position c.168. (GenBank accession No. U63008).

${ }^{\mathrm{b}}$ The mutations on two AKU chromosomes remain to be identified. 


\section{Results}

\section{Mutations in the HGO Gene}

All 14 exons of the $H G O$ gene were screened in the 19 index cases by SSCP analysis and direct sequencing of aberrant fragments. In total 10 different mutations were found (Table 1), five of which had been reported in earlier studies. ${ }^{5-8}$ The Gly161Arg (c.648G > A) mutation which we had previously described in a single family $^{6}$ turned out to be the most prevalent AKU mutation in both Slovak and Czech patients. It has been observed on 15 of the 38 unrelated AKU chromosomes studied, thus accounting for $39.5 \%$ of all disease alleles in the 19 index patients. Five novel mutations have been identified.

1) An exchange of the first nucleotide of the splice acceptor site in intron 1 (c.183-1G $>$ A) which is likely to abolish effective splicing of exon 2 . This is the second most frequent mutation seen in our cohort, affecting five index patients of Slovak and Czech origin, and representing a further $13 \%$ of all independent AKU alleles studied.

2) A missense mutation Leu25Pro (c.241T $>$ C) has been observed on both alleles in one German patient.

3) The splice donor site of intron 5 was found mutated (c. $509+1 \mathrm{G}>\mathrm{A})$ on one chromosome in a Czech patient. Again, this should lead to skipping of exon 5 .

4) A single Slovak patient was heterozygous for the mutation Gly270Arg (c.975G > A).
5) An insertion of a seventh cytosine in a row of six (c.1278insC) has been observed in three apparently unrelated Slovak families originating from the same location in north-west Slovakia (Figure 2). This truncating mutation predicts a frame shift after Pro370 and a premature stop codon at amino acid position 374 .

Twelve of the patients were 'pure' homozygotes and 18 were compound heterozygotes; in two of the latter the second allele remained unidentified. The combination of alleles in affected individuals are evident from Table 2. Except for two mutations (Leu25Pro and Met368Val) all sequence alterations could be traced in the families of the index patients, and all segregated with the disease status in the expected recessive manner. In one large pedigree the four affected fourth degree cousins shared the familial c.1278insC mutation, whilst two other mutations (c.183-1G $>$ A and Gly161Arg) had been introduced by unrelated spouses.

\section{Recombinant Expression of HGO Mutations}

The murine HGO cDNA was expressed in E. coli and the activity of the recombinant enzyme was determined following the conversion of homogentisate to maleylacetoacetate spectrometrically at $330 \mathrm{~nm} .{ }^{10}$ The human AKU mutations Gly161Arg, Met368Val and c.1278insC were introduced into the wild-type murine cDNA by site-directed mutagenesis. All three mutations reduced the enzyme activity to background levels (Figure 1).

Table 2 HGO allele combinations in 30 alkaptonuria patients

\begin{tabular}{|c|c|c|c|c|c|c|c|c|c|c|}
\hline & c.183-1G>A & Leu25Pro & c. $509+1 G>A$ & c.642ins $G$ & Gly161Arg & Pro230Ser & Gly270Arg & Val300Gly & Met368Val & c.1278ins C \\
\hline \multicolumn{11}{|l|}{ c. $183-1 \mathrm{G}>\mathrm{A}$} \\
\hline Leu25Pro & & 1 & & & & & & & & \\
\hline \multicolumn{11}{|l|}{ c. $509+1 \mathrm{G}>\mathrm{A}$} \\
\hline c.642insG & & & & 2 & & & & & & \\
\hline Gly161Arg & 3 & & 1 & 2 & 6 & & & & & \\
\hline Pro230Ser & & & & & & 1 & & & & \\
\hline \multicolumn{11}{|l|}{ Gly270Arg } \\
\hline Val300Gly & 2 & & & & 2 & & & & & \\
\hline Met368Val & & & & & 1 & & & & 2 & \\
\hline c.1278insC & 3 & & & & 1 & & 1 & & & \\
\hline unknown & 1 & & & & & & & & & 1 \\
\hline
\end{tabular}


Allelic Association Studies and Geographical Origin of the HGO Mutations in Slovakia

From our mutation analysis it was evident that the high prevalence of AKU in Slovakia is caused by a variety of mutations. In order to determine the chromosomal background of the different mutations, the intragenic markers D3S4556 and D3S4497 were typed in the Slovak AKU families. This allowed a 'mini' haplotype to be constructed for each AKU chromosome. The second chromosomes of both the parents and grandparents were used as controls for the frequency of the non-AKU haplotypes. In Table 3 the observed haplotypes and their association with the four recurrent HGO mutations are listed.

To determine the geographical origin of the different HGO mutations in Slovakia, the birthplaces of the two oldest known gene carriers from each AKU family were plotted on the map of Slovakia (Figure 2). Seven families bearing five different mutations originate from

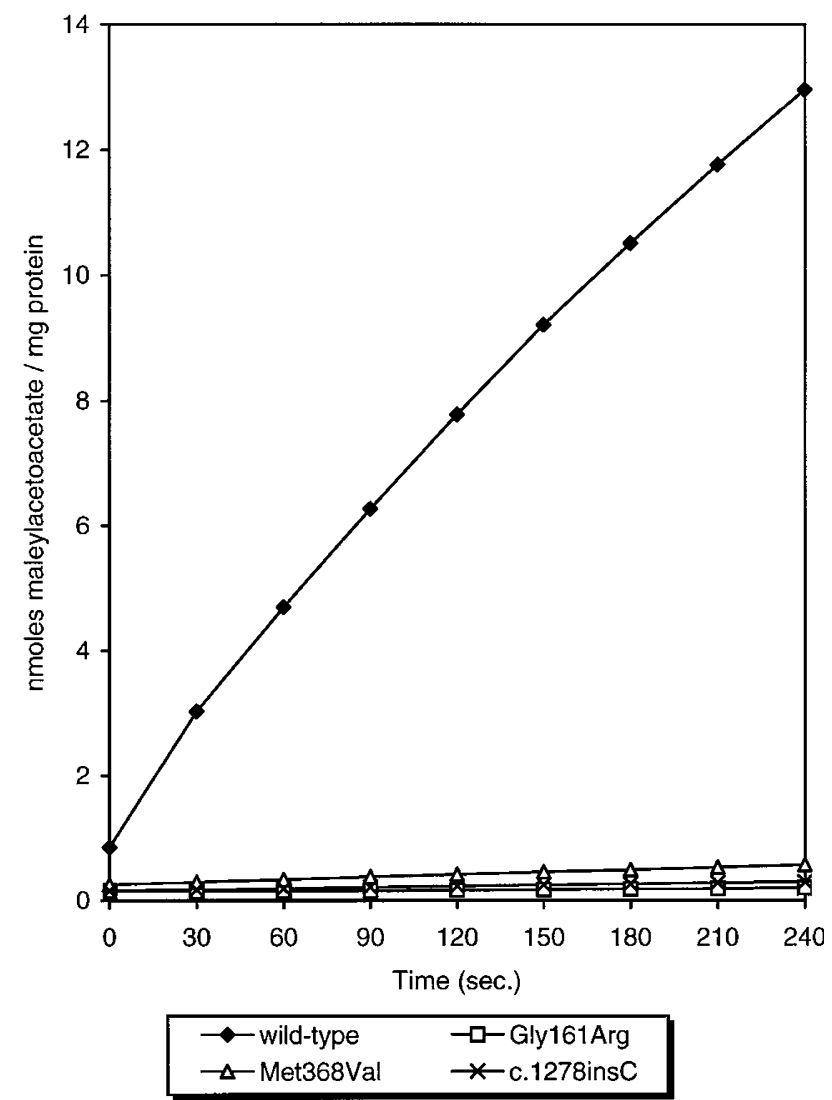

Figure 1 Activity of recombinant wild-type and mutated $H G O$ enzymes. The conversion of homogentisate to maleylacetoacetate was measured in recombinant wild-type and mutant E. coli extracts as described in Methods. a small location in north-west Slovakia called Kysuce, close to both the Czech and Polish borders. The origins of the other mutations, in particular the most prevalent Gly161Arg mutation, are scattered across the country.

\section{Discussion}

\section{Allelic Heterogeneity of Alkaptonuria}

Our study brings to 21 the number of HGO mutations causing alkaptonuria and demonstrates a remarkable allelic heterogeneity of the disease in Central Europe. Two mutations (c.183-1G > A and Gly161Arg) account for 20 of the 38 disease alleles in the index cases $(52.6 \%)$.

In particular, it is clear from our data that the high incidence of AKU in Slovakia cannot only be explained by a single founding event. In total seven different mutations have been identified in 12 families from that country. Three mutations (c.624insG, Gly270Arg, c.1278insC) have not yet been found outside Slovakia. Interestingly, two of the mutations observed in Slovak patients, Pro230Ser and Val300Gly, were reported previously in Spanish, Turkish, French and German families. $^{7}$

The spectrum of $\mathrm{HGO}$ alleles in the five AKU patients from the Czech Republic overlaps the Slovak mutations with one exception. The splice site mutation c. $509+1 \mathrm{G}>\mathrm{A}$ affects the same nucleotide as a mutation described in a Dutch patient. ${ }^{7}$ However, whereas a $\mathrm{G}$ to $\mathrm{T}$ transversion was reported there, we have found a $G$ to $A$ transition at the same position. Both base exchanges, however, replace the canonical first $\mathrm{G}$ of the consensus donor splice site and are therefore likely to cause skipping of the preceding exon 5.

Three of the four German AKU patients share the Met368Val mutation which has been previously reported in one French and one German family. ${ }^{7}$ It may therefore represent a more frequent $\mathrm{HGO}$ mutation in Central Europe. The fourth patient from Germany was homozygous for the Leu25Pro mutation described here for the first time.

\section{Recombinant Expression of HGO Mutations}

All missense mutations reported in this study affect amino acids which are conserved in the $H G O$ genes of all species sequenced so far (data not shown). Therefore, the mutagenesis of these sites in the cloned murine cDNA which shows $88.4 \%$ similarity to the human sequence was expected to have functional effects. On expression in $E$. coli, the two missense mutations 
Table 3 Allelic associations on Slovak AKU chromosomes

\begin{tabular}{|c|c|c|c|c|}
\hline \multirow[b]{2}{*}{ Nucleotide position } & \multirow[b]{2}{*}{ Amino acid exchange } & \multirow[b]{2}{*}{ No. of families } & \multicolumn{2}{|c|}{ Marker alleles of the familial $A K U$ haplotype } \\
\hline & & & D3S4497 (HGO-2) & D3S4556 (HGO-3) \\
\hline \multirow[t]{5}{*}{ c. $183-1 \mathrm{G}>\mathrm{A}$} & splice site & 5 & 179 & 199 \\
\hline & & & 179 & 199 \\
\hline & & & 179 & 199 \\
\hline & & & 179 & 199 \\
\hline & & & 179 & 199 \\
\hline \multirow[t]{2}{*}{ c.624insG } & Gly152fs & 2 & 185 & 187 \\
\hline & & & 185 & 187 \\
\hline \multirow[t]{12}{*}{ c. $648 \mathrm{G}>\mathrm{A}$} & Gly161Arg & $11^{\mathrm{a}}$ & 189 & 191 \\
\hline & & & 189 & 191 \\
\hline & & & 189 & 191 \\
\hline & & & 189 & 191 \\
\hline & & & 189 & 191 \\
\hline & & & 189 & 191 \\
\hline & & & 189 & 191 \\
\hline & & & 189 & 191 \\
\hline & & & 189 & 195 \\
\hline & & & 189 & 195 \\
\hline & & & 189 & 197 \\
\hline & & & 191 & 191 \\
\hline \multirow[t]{3}{*}{ c.1278insC } & Pro370fs & 3 & 177 & 187 \\
\hline & & & 177 & 193 \\
\hline & & & 177 & 193 \\
\hline
\end{tabular}

a the mutation was introduced into one large pedigree by two different spouses on different haplotypes.

(Gly161Arg and Met368Val) and the frame-shifting insertion (c.1278insC) all cancelled out the activity of the recombinant enzyme. This is proof of their causal role in the pathophysiology of alkaptonuria.

\section{Geographic Origin of HGO Mutations in Slovakia and Allelic Association Studies}

Slovakia has the highest incidence of AKU world-wide with 1 in 19000 inhabitants. ${ }^{14}$ We have traced the birthplaces of the oldest known gene carriers in each family in order to assess the geographic origin of the various mutations in historical times (Figure 2). A remarkable clustering and a high allelic heterogeneity of AKU was found in the Kysuce district in north-west Slovakia. Seven families representing five different mutations originate from a population of only 125500 inhabitants. The c.1278insC mutation was exclusively found in this region. This high incidence is likely to reflect the low mobility of this rural population up to the middle of the 20th century. The diversity of mutations in this area is more difficult to explain but not without precedence. Allelic heterogeneity has been reported for a number of genes in small, isolated populations ${ }^{17-20}$ and the possible mechanisms have been discussed. ${ }^{21}$ Typically, such populations show a high degree of consanguineous marriages, which also holds true for this Slovak population in the past. All other mutations, in particular the two prevalent ones, c.183-1G > A and Gly161Arg, are found all over the country.

From the allelic association studies of the two intragenic markers D3S4497 and D3S4556 it is evident that in eight of the 11 Slovak families the Gly161Arg mutation resides on the haplotype 189-191. More strikingly, the c.183-1G > A transition occurred on the haplotype 179-199 in all five families (Table 3). Both haplotypes have not been observed on the non-AKU control chromosomes and are therefore not likely to be frequent in the general population. This suggests independent ancestral founders for each of these mutations and subsequent genetic drift. In contrast, the three families with the c.1278insC mutation, all originating from the Kysuce district, show two different haplotypes (Table 3 ).

In conclusion, the molecular epidemiology of alkaptonuria in Slovakia has shown that the disease is caused 


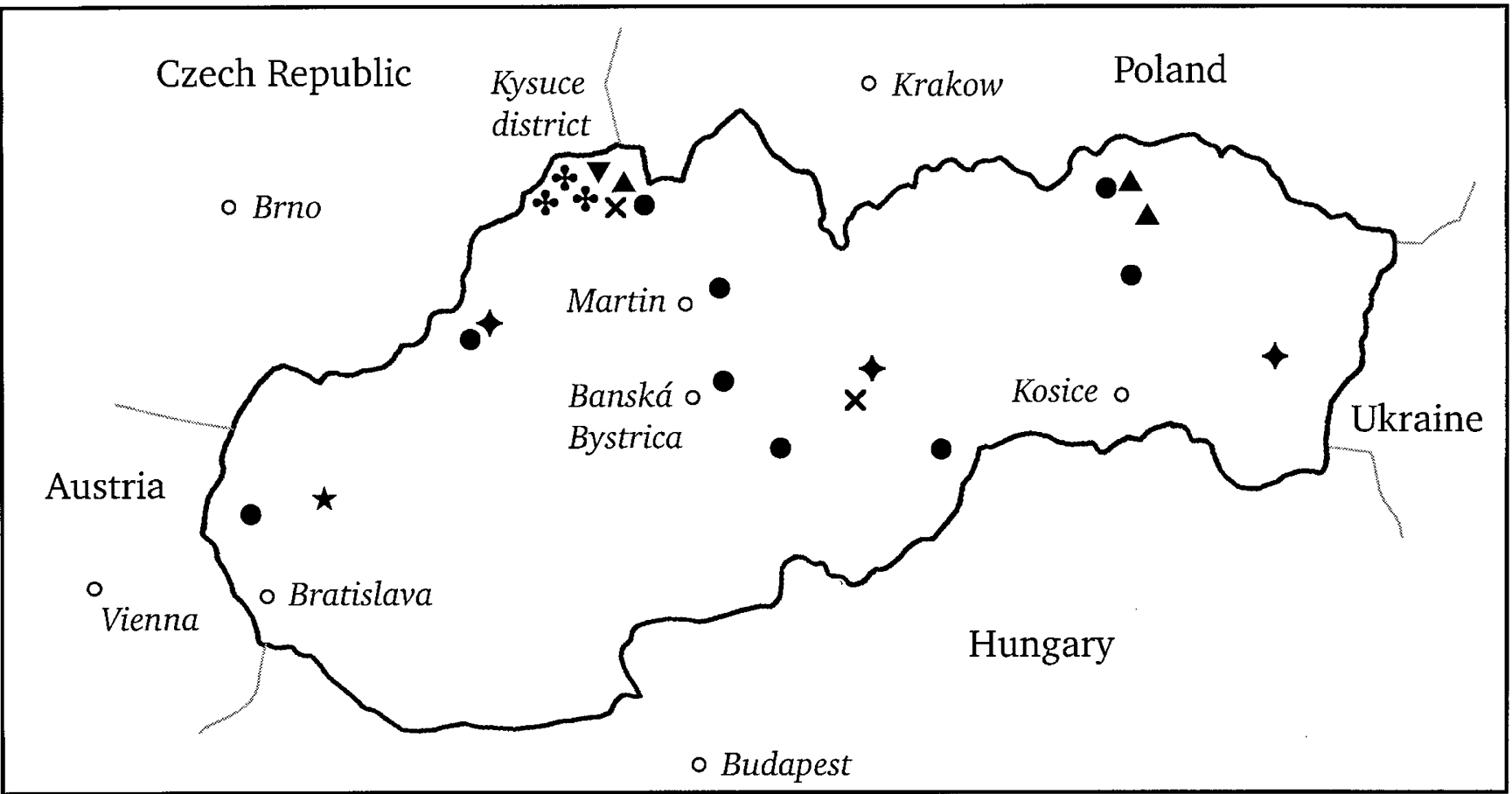

Figure 2 Distribution of HGO mutations in Slovakia. The birthplaces of the oldest known mutation carriers in each AKU family have been determined. Mutations are represented by the following symbols: $\mathbf{\Delta}=\mathrm{c} .183-1 \mathrm{G}>\mathrm{A} ; \times \mathbf{x}=\mathrm{c} .624 \mathrm{insG} ; \bullet=\mathrm{Gly} 161 \mathrm{Arg}$; $\star=$ Pro230Ser; $\boldsymbol{\nabla}=$ Gly270Arg; $\uparrow=$ Val300Gly; $\bullet=$ c.1278insC. For orientation, major cities are marked by open circles.

by a diversity of mutations. The results from the Kysuce district may represent another example of the 'La Réunion paradox', ie the high prevalence and allelic heterogeneity within a small, isolated population. ${ }^{19} \mathrm{~A}$ high mutation rate and selective advantage of heterozygotes could be contributing factors. However, there is no evidence that either one might apply to AKU. It is known that several ethnic groups have immigrated into Slovakia at different times in history, including Ukrainian, Hungarian and Romanian people. Therefore, it is conceivable that several founders could have contributed to the pool of HGO alleles.

The prevalence of two mutations which are easily detectable by PCR-RFLP and together cover about $52 \%$ of all disease alleles provide a basis for a rapid heterozygote screening in the Slovak population.

\section{References}

1 La Du BN: Alcaptonuria. In: Scriver CR, Beaudet AL, Sly WS, Valle D (eds). The Metabolic Basis of Inherited Disease. McGraw-Hill, New York, 1989, vol. II, pp 775-790.
2 O'Brien WM, La Du BN, Bunim JJ: Biochemical, pathologic and clinical aspects of alcaptonuria, ochronosis and ochronotic arthropathy: review of world literature (1584-1962). Am J Med 1963; 34: 813-838.

3 La Du BN, Zannoni VG, Laster I, Seegmiller JE: The nature of the defect in tyrosine metabolism in alkaptonuria. J Biol Chem 1958; 230: 251-260.

4 Fernandez-Canon JM, Penalva MA: Molecular characterisation of a gene encoding a homogentisate dioxygenase from Aspergillus nidulans and identification of its human and plant homologues. $J$ Biol Chem 1995; 270: 21199-21205.

5 Fernandez-Canon JM, Granadino B, Beltran-Valero de Bernabe $\mathrm{D}$ et al: The molecular basis of alkaptonuria. Nat Genet 1996; 14: 19-24.

6 Gehrig A, Schmidt SR, Muller CR, Srsen S, Srsnova K, Kress W: Molecular defects in alkaptonuria. Cytogenet Cell Genet 1997; 76: 14-16.

7 Beltran-Valero de Bernabe D, Granadino B, Chiarelli I et al: Mutation and polymorphism analysis of the human homogentisate 1,2-dioxygenase gene in alkaptonuria patients. Am J Hum Genet 1998; 62: 776-784.

8 Ramos SM et al: Molecular diagnosis of alkaptonuria mutation by analysis of homogentisate 1,2 dioxygenase mRNA from urine and blood. Am J Med Genet 1998; 78 192-194.

9 Higashino K et al: A novel point mutation associated with alkaptonuria. Clin Genet 1998; 53: 228-229.

10 Schmidt SR, Muller CR, Kress W: Murine liver homogentisate 1,2-dioxygenase. Purification to homogeneity and novel biochemical properties. Eur J Biochem 1995; 228 425-430. 
11 Schmidt SR, Gehrig A, Koehler MR, Schmid M, Muller $\mathrm{CR}$, Kress W: Cloning of the homogentisate 1,2-dioxygenase gene, the key enzyme of alkaptonuria in mouse. Mamm Genome 1997; 8: 168-171.

12 Kress W, Schmidt SR, Halliger-Keller B, Montagutelli X, Muller CR: The genetic defect in the alkaptonuric mouse (aku). Mamm Genome 1999; 10: 68-70.

13 Milch RA: Studies in alcaptonuria: Inheritance of 47 cases in eight highly inter-related Dominican kindreds. $A m J$ Hum Genet 1960; 12: 76-85.

14 Srsen S, Cisarik F, Pasztor L, Harmecko L: Alkaptonuria in the Trencin District of Czechoslovakia. Am J Med Genet 1978; 2: 159-166.

15 Koska L, Srsen S: A simple urine screening test for alcaptonuria. N Engl J Med 1977; 297: 1471-1472.

16 Granadino B, Beltran-Valero de Bernabe D, FernandezCanon JM, Penalva MA, Rodriguez de Cordoba S: The human homogentisate 1,2-dioxygenase (HGO) gene. Genomics 1997; 43: 115-122.
17 Bach G, Moskowitz SM, Tieu PT, Matynia A, Neufeld EF: Molecular analysis of Hurler syndrome in Druze and Muslim Arab patients in Israel: multiple allelic mutations of the IDUA gene in a small geographic area. Am J Hum Genet 1993; 53: 330-338.

18 Heinisch U, Zlotogora J, Kafert S, Gieselmann V: Multiple mutations are responsible for the high frequency of metachromatic leukodystrophy in a small geographic area. Am J Hum Genet 1995; 56: 51-57.

19 Richard I, Broux O, Allamand V et al: Mutations in the proteolytic enzyme calpain 3 cause limb-girdle muscular dystrophy type 2A. Cell 1995; 81: 27-40.

20 Rund D, Cohen T, Filon D et al: Evolution of a genetic disease in an ethnic isolate: beta-thalassemia in the Jews of Kurdistan. Proc Natl Acad Sci USA 1991; 88: 310-314.

21 Zlotogora J, Gieselmann V, Bach G: Multiple mutations in a specific gene in a small geographic area: a common phenomenon? Am J Hum Genet 1996; 58: 241-242. 